\title{
Alternative Estimating Methodologies of the UK Industry Cost of Equity Capital: The Impact of 2007 Financial Crisis and Market Volatility
}

\author{
Panayiota Koulafetis ${ }^{1}$ \\ ${ }^{1}$ School of Economics and Finance, Queen Mary University of London, UK \\ Correspondence: Panayiota Koulafetis, School of Economics and Finance, Queen Mary University of London, \\ Mile End Road, London, E1 4NS, UK. Tel: 44-020-7882-8846. E-mail: p.koulafetis@ qmul.ac.uk
}

Received: November 11, 2015

Accepted: November 23, $2015 \quad$ Online Published: December 25, 2015

doi:10.5539/ijef.v8n1p111

URL: http://dx.doi.org/10.5539/ijef.v8n1p111

\begin{abstract}
We compare estimates of the UK industry cost of equity capital between the unconditional beta Arbitrage Pricing Model (APM), the conditional beta APM and the Capital Asset Pricing Model (CAPM). A statistically significant eight-factor APM leads to the best estimates of the UK industry cost of equity capital. During our full sample time period any of the APMs, unconditional APM or conditional APM, do a much better job than the CAPM.

However at times of extreme market volatility during the 2007 financial crisis, the conditional APM is the best model with the least errors. During a financial crisis investors and market participants' expectations are revised. Economic forces at play include: increased market uncertainty, increased investors' risk aversion and capital scarcity. We find that the macroeconomic factors impeded in the Conditional APM that vary over time using the latest information in the market, incorporate the economic forces at play and capture the extreme market volatility. Our findings have direct implications in the financial markets for regulators, corporate financial decision makers, corporations and governments.
\end{abstract}

Keywords: APM, CAPM, conditional asset pricing, unconditional asset pricing, cost of equity capital

\section{Introduction}

Estimates of cost of equity capital form the cornerstone for a wide range of company valuation applications and corporate capital budgeting decisions. Nevertheless, its estimation remains a matter of considerable debate and uncertainty both in the academic literature and among practicing professionals.

The Capital Asset Pricing Model (CAPM) has been widely used in cost of capital calculations. However Fama and French (1992) suggest that standard market indexes are not mean variance efficient. Fama and French (1997) identify the choice of the asset-pricing model as one of the three problems in cost of capital estimates (premiums and betas). However they do not take a stance on which is the right asset pricing model rather they use both the CAPM and their three firm specific factor model and find that both models entail large errors.

The problem of inaccuracy in estimating the cost of equity capital has major implications. In regulatory contexts, setting prices for regulated industries, water, gas, airport landing charges etc; regulated companies need to charge reasonable prices for their products and services. The regulatory commissions decide on what is reasonable on the assumption that these companies have to earn a fair rate of return for their equity investors. To come up with this fair rate of return, they need estimates of Equity Risk Premiums (ERP). If regulated companies use higher ERP this will translate into higher cost of equity and subsequently higher prices for their customers.

There are many other practical implications in estimating the cost of equity capital and determining what's the right number to use. Corporations and governments have to set aside funds to meet future obligations. The amount set aside depends on their expectations of the rate of return they obtain from investing in equity markets; ultimately the ERP. If their expectations of the ERP are incorrect and end up with a shortfall in order to meet liabilities, then governments will have to raise taxes and corporations will have to reduce profits.

The objective of this paper, in the first known attempt, is to investigate the impact of model choice on the estimation of the UK industry cost of equity capital using macroeconomic factors and offer comparative estimates under three alternative specifications: (i) the unconditional-constant beta Arbitrage Pricing Model 
(APM); (ii) the conditional-time varying beta APM and iii) the CAPM. Our APM estimates are based on eight statistically significant macroeconomic factors. We contribute to the literature by identifying new factors that are statistically significant in UK; the S\&P 500 and UK stock exchange turnover.

We also extent the existing literature by estimating the prices of risk for the UK industry cost of equity capital using the Non-Linear Seemingly Unrelated Regression (NLSUR) estimates. Elton, Gruber and Mei (1994), claim that an estimation procedure worthwhile exploring in the future involves estimating the prices of risk via seemingly unrelated regression. This technique allows us to impose the constraint that the price of risk for each factor is the same for all industries, a basic principle of the arbitrage pricing theory.

A key problem in the cost of equity capital calculation relates to the calculation of betas and whether these vary or remain constant. Given the evidence of time-varying conditional betas for portfolio returns by Ferson and Harvey (1991, 1993, 1999), we allow betas to depend on instruments and model betas as linear functions of predetermined instruments. Ferson and Harvey (1999) find that conditional versions of models with time-varying betas provide some improvement, and that their results carry implications for risk analysis, performance measurement, cost of equity calculations and other applications. Our study contributes to the literature by assessing the performance of conditional betas in estimating the cost of equity capital.

On the other hand there has been evidence by Ghysels (1998) who finds pricing errors with constant traditional beta models are smaller than with conditional CAPM. He shows that the conditional CAPM fails to capture the dynamics of beta risk. He argues that betas change through time very slowly and linear factor models like the conditional CAPM may have a tendency to overstate the time variation. Thus, they produce time variation in beta that is highly volatile, leading to large pricing errors. He concludes that it is better to use the static CAPM in pricing, as we do not have a proper model that captures time variation in betas correctly.

Thus following the ambiguity in the literature we also estimate constant betas. Our study aims to shed more light on whether unconditional-constant or conditional-time varying asset pricing models are better to estimate the industry cost of equity capital with the least error. Although there is empirical evidence on time variation in betas, more research has to be carried out as to how the incorporated time variation performs relative to constant models.

Finally, our comparison of the industry cost of equity capital based on CAPM and the two specifications of APM, identifies the CAPM as the worst performer on the basis of comparative mean square errors. Our evidence that the APM is much better than the CAPM is consistent with US evidence. However our study extends the existing literature by showing that both unconditional and conditional versions of the APM are better than the CAPM.

We find that during our full sample time period, the conditional or unconditional beta property of a model is not so critical; as it is to identify a model that includes the priced factors in the market. However from the beginning of the 2007 financial crisis the conditional APM proves to be the best model with the least errors. When equity markets collapse, there is a traditional so called "flight to quality" with investors seeking to transfer their wealth to less risky assets, such as sovereign bonds. What we have experienced during the recent financial crisis, is that there has been a subsequent deterioration of sovereign credits, which has exacerbated the uncertainty of returns over the medium to long term investment horizon. The time varying nature of the conditional APM captures not only the macroeconomic forces at play but also the extreme market volatility.

The economic repercussions of our findings suggest that the cost of equity capital assumed by practitioners should be adjusted to new market realities. Major shocks to the financial system, the collapse of a large company or sovereign entity etc. should be recognised and adjust the cost of equity capital. This finding has important implications; if long-term historic averages or estimates of cost of equity capital under normal market conditions are used during periods of financial crisis this leads to errors as it will underestimate the risks in the markets.

The paper is organised as follows: Section 2 provides the related literature review. Section 3 describes the data and competitive models used in the paper for the industry cost of equity capital estimation. Section 4 discusses the estimation of the prices of risk via NLSUR for all models. Section 5 explains the estimation of the unconditional-constant and conditional-time varying betas. Section 6 discusses the CAPM. Section 7 discusses the industry cost of equity capital and errors of each model; the unconditional-constant beta APM, the conditional-time varying beta APM and the CAPM. Section 8 concludes.

\section{Related Literature}

The estimation of the cost of equity capital has been an important focus in finance. There are alternative models for estimating the cost of equity capital. Most of the related existing research based on asset pricing models focuses on the traditional CAPM, firm-specific factor models that some argue that they lack theoretical basis, as well as comparisons between statistical factor APM and macroeconomic factor APM employing mainly the two 
step Fama-Mac Beth methodology or using historic averages as estimates for expected premiums.

The CAPM has been the dominant methodology in the last decades but evidence has cast doubt in its robustness in describing expected returns. Fama and French (1993) proposed an empirical three-factor model that relies, in addition to the usual market risk premium, on size and a book-to-price premiums. Fama and French (1992, 1996, 1997, 1999, 2004, and 2006) make a strong case that the CAPM fails to describe the cross-section of stock returns. Further Fama and French (2012) show in the four regions (North America, Europe, Japan, and Asia Pacific) that there are value premiums in average stock returns that, except for Japan, decrease with size. The standard CAPM beta cannot explain the cross-section of unconditional stock returns (Fama \& French, 1992) or conditional stock returns (Lewellen \& Nagel, 2006).

Lewellen and Nagel (2006) show that the conditional CAPM performs nearly as poorly as the unconditional CAPM. They claim that the conditional CAPM does not explain asset-pricing anomalies like book-to-market $(\mathrm{B} / \mathrm{M})$ or momentum. They argue that covariances are simply too small to explain large unconditional pricing errors. They claim that betas vary considerably over time, but not enough to generate significant unconditional pricing errors.

Cooper and Priestley (2013) assess the asset pricing implications of their stock return predictability results by estimating a conditional version of the international CAPM and an international Fama and French (1998) two-factor model. They find that scaling the CAPM risk factor as well as the two Fama and French (1998) world risk factors with conditioning information results in a better description of the cross-sectional pattern in average returns for country-level portfolios and portfolios formed on firm characteristics.

There is an active debate in the literature as to the relative performance of conditional betas versus unconditional betas. Elton, Gruber, and Blake (2012) examine mutual fund timing ability and find that using a one-index model, management appears to have positive and statistically significant timing ability. When a multi-index model is used, they find that timing decisions do not result in an increase in performance, whether timing is measured using conditional or unconditional betas. Ferson and Schadt (1996) explore the impact of conditioning betas on mutual fund performance. They study timing in the context of a single-factor model and find that conditioning beta on a small set of variables changes many of the conclusions about the selection and timing ability of mutual fund managers.

The literature on cost of equity capital estimation has so far focused on the traditional CAPM and APM using individual company data mainly on the utility sector, and firm specific models. Bower et al. (1984), present evidence that the APM may lead to different and better estimates of expected return than the CAPM in their attempt to estimate the cost of equity for US utility stock returns. Using the Fama-MacBeth (1972) methodology they conclude in favor of the APM estimates.

Goldenberg and Robin (1991), use the CAPM and the APM to estimate the cost of equity for 31 US electric utilities. They find that the statistical factors APM method is found to produce significantly different estimates depending on the number of factors specified and the set of firms' factors analyzed. Pettway and Jordan (1987) extent Bowers et al. (1984) by comparing the relative efficiency of the CAPM and APM in the true forecasting sense of predicting future equity returns. Using weekly data on US electric utilities, they find the APM provides better forecasts of future returns than the CAPM.

Schink and Bower (1994), test the Fama and French (1993) three-factor model's ability to measure the cost of equity for New York electric utilities. For estimates of the expected premium they use historical averages. They find that although the average allowed return and the estimated cost of equity are almost identical over the 1980-1991, the allowed return figures have a wider dispersion by case and by year. Elton, Gruber and Mei (1994), describe an APM that can be used to determine the cost of equity for any company. They use the Fama-MacBeth methodology and find that the required return on common stock depends on its sensitivity to a set of indexes which include the return on the market but also include unexpected changes in the level of interest rates, the shape of the yield curve, exchange rates, production and inflation.

For the estimation of the cost of equity capital we also need accurate estimates of the prices of risk. The literature on the estimation of the cost of equity capital (Schink \& Bower, 1994; Fama \& French, 1997) use historic averages for the estimation of the factor premiums. Schink and Bower (1994), claim that estimates of expected factor premiums can be improved by considering data beyond historic averages and that the historical averages for the factors provide a simple but not the best estimate for the expected premiums.

Elton, Gruber, and Mei (1994) claim that an estimation procedure worth exploring in the future involves estimating the prices of risk via seemingly unrelated regression. We address this point in our paper and estimate 
the prices of risk via NLSUR for the industry cost of equity capital calculation.

Further evidence on the imprecision of cost of equity estimates based on CAPM and the three-factor model is shown by Fama and French (1997). Gregory and Michou (2009) explore firm specific variable models in UK. They replicate the Fama and French (1997) US analysis for UK industries, but additionally investigate the industry cost of equity capital obtained from a conditional CAPM, the Cahart (1997) four factor model (factors include the size, book to market, momentum and the market factor), and the Al-Horani, Pope and Stark (2003) R\&D model (the momentum factor in the four factor model is replaced by a research and development (R\&D) factor). In line with the Fama-French US results, they find the performance of all the models disappointing. Claire, Priestley and Thomas (1998) based on 100 UK stock return data quoted on the London stock exchange during 1980-1993 find no role for the Fama and French (1992) variables when the CAPM is estimated using the NLSUR.

\section{Data and Model Description}

We estimate the industry cost of equity capital using three alternative models: The CAPM, the unconditionalconstant beta APM and the conditional-time varying APM.

The monthly industry indices, macroeconomic factors and instrumental variables are obtained from Bloomberg for the period December 1992 to March 2014. The indices are value weighted. Our data set consists of 28 industries, 522 companies with a total market value of $£ 1,612.907$ billion. Table 1 describes the industry indices; Table 2 describes the macroeconomic factors and Table 3 the instrumental variables.

Table 1. Industry indices

\begin{tabular}{|c|c|c|c|c|}
\hline Symbol & Industry & No of Firms & Market Cap. £Billions & $\%$ \\
\hline BANK & FTSE ASX Banks Index & 6 & 264.61 & $16.4 \%$ \\
\hline MNG & FTSE ASX Mining Index & 22 & 175.13 & $10.9 \%$ \\
\hline PHRM & FTSE ASX Pharmaceuticals \& Biotechnology & 8 & 160.46 & $9.9 \%$ \\
\hline SUPP & FTSE ASX Support Services Index & 51 & 95.7 & $5.9 \%$ \\
\hline LIFE & FTSE ASX Life Insurance Index & 12 & 93.3 & $5.8 \%$ \\
\hline ТОВС & FTSE ASX Tobacco Index & 2 & 90.87 & $5.6 \%$ \\
\hline BEVG & FTSE ASX Beverages Index & 6 & 110.36 & $6.8 \%$ \\
\hline LEIS & FTSE ASX Travel Leisure Index & 34 & 86.68 & $5.4 \%$ \\
\hline INVC & FTSE ASX Investment Instruments & 177 & 15.17 & $0.9 \%$ \\
\hline MEDA & FTSE ASX Media Index & 24 & 71.1 & $4.4 \%$ \\
\hline FOOD & FTSE ASX Food Producers Index & 11 & 65.08 & $4.0 \%$ \\
\hline OTHR & FTSE ASX Fin Services Index & 26 & 57.78 & $3.6 \%$ \\
\hline RETG & FTSE ASX Gen Retailers Index & 23 & 48.34 & $3.0 \%$ \\
\hline AERO & FTSE ASX Aerospace \& Defence & 9 & 44.44 & $2.8 \%$ \\
\hline FDRT & FTSE ASX Food Drug Retailers Index & 7 & 39.63 & $2.5 \%$ \\
\hline TELE & FTSE ASX Fixed Line Telecommunications & 6 & 37.67 & $2.3 \%$ \\
\hline INSU & FTSE ASX Nonlife Insurance Index & 11 & 25.92 & $1.6 \%$ \\
\hline ENGN & FTSE ASX Industrial Engineering Index & 12 & 20.54 & $1.3 \%$ \\
\hline CONS & FTSE ASX Construct Material Index & 12 & 18.33 & $1.1 \%$ \\
\hline INFT & FTSE ASX Tech Hardware Index & 9 & 17.14 & $1.1 \%$ \\
\hline CHEM & FTSE ASX Chemicals Index & 7 & 14.36 & $0.9 \%$ \\
\hline SOFT & FTSE ASX Software \& Computer Service & 13 & 12.2 & $0.8 \%$ \\
\hline ELTR & FTSE ASX Electronic \& Electrical Equipment & 13 & 11.39 & $0.7 \%$ \\
\hline HLTH & FTSE ASX Health Care Equipment and Services & 6 & 12.73 & $0.8 \%$ \\
\hline PERC & FTSE ASX Personal Goods Index & 4 & 9.43 & $0.6 \%$ \\
\hline AUTO & FTSE ASX Automobiles Parts Index & 1 & 6.06 & $0.4 \%$ \\
\hline TRAN & FTSE ASX Industrial Transportation Index & 8 & 8.48 & $0.5 \%$ \\
\hline HOUS & FTSE ASX Leisure Goods Index & 2 & 0.00716 & $0.0004 \%$ \\
\hline TOTAL & & 522 & $1,612.91$ & $100.0 \%$ \\
\hline
\end{tabular}

Note. The monthly industry indices are obtained from Bloomberg for the period December 1992 to March 2014. The indices are value weighted.

Table 2 describes the unanticipated macroeconomic factors, generated using ARIMA models. We investigate 
several ARIMA models for each series, but select only one ARIMA order combination to represent each series based on the residuals being white noise (mean zero and serial uncorrelated). Inspection of individual autocorrelation coefficients can be provided upon request.

Table 2. Macroeconomic factors

\begin{tabular}{llcc}
\hline Symbol & Unanticipated Macroeconomic Factors & (AR,I,MA) & Durbin Watson \\
\hline FTSE & Log return (Note 1) of FTSE All-Share Index & $(0,0,1)$ & 2.00 \\
SP & Log return of S\&P 500 Index & $(12,0,1)$ & 2.00 \\
TURN & Log return of London Stock Exchange Equity Turnover & $(12,0,1)$ & 2.01 \\
MO & Log return of UK Money Supply M2 & $(1,0,0)$ & 1.98 \\
EX & Log return of The Great Britain Pound (GBP)-United States Dollar (USD) Exchange Rate & $(1,0,0)$ & 1.99 \\
TERM & The spread of 20 Year UK Government Bonds and 1 Month UK Treasury Bills & $(1,1,0)$ & 2.02 \\
DEF & The spread of GBP 10 year SWAP and 20 Year UK Government Bonds & $(1,1,0)$ & 2.03 \\
INFL & Log return of UK Consumer Price Index (CPI) & $(12,0,0)$ & 2.06 \\
\hline
\end{tabular}

Table 3 describes the instrumental variables used in the conditional time varying APM.

Table 3. Instrumental variables

\begin{tabular}{ll}
\hline Symbol & Instrumental Variables \\
\hline$I T B 1_{t-1}$ & One-month Treasury bill rate change lagged one month \\
$I D I V_{t-1}$ & Dividend yield on FT all share price index change lagged one month \\
$I T S_{t-1}$ & The spread of 20 Year UK Government Bonds and 1 Month UK Treasury Bills lagged one month \\
$I F T_{t-1}$ & Log return on FT all share price index lagged one month \\
\hline
\end{tabular}

We use the same methodology-Non-Linear Seemingly Unrelated Regression (NLSUR)-for estimating the price of risk for each of the factors included in each model. The CAPM contains only the market factor while both APMs include the same set of macroeconomic factors. The selection of macroeconomic factors for the APM models is guided by the findings of the extant literature. We investigate the significance of factors that can affect industry returns by having an impact on the discount rate or the earnings stream. Further one of the main components of the Arbitrage Pricing Theory (APT) is that anticipated changes are expected and have already been incorporated into expected returns. It's the unanticipated returns that are important; since the betas measure the sensitivity of returns to unanticipated movements in the factors. For example earnings expectations are embedded in firm value and unanticipated changes in the expectations influence individual firm and industry value.

The APT does not specify the factors in the APM. It follows the concept that any systematic factor that affects the pricing of the economy or influences dividends would also impact equity returns. Since stock prices can be expressed as expected discounted dividends, it follows that any systematic variable that can change discount rates and expected cash flows affects stock returns. Following this principle we test a number of factors and conclude on an eight factor APM. We derive the unexpected components of the factors by an Autoregressive Integrated Moving Average (ARIMA) model for each series. We investigate several ARIMA models for each series but select only one ARIMA order combination to represent each series based on the residuals being white noise (mean zero and serially uncorrelated). Table 2 also shows the ARIMA model for each factor and the associated Durbin Watson. In order to arrive to our final model we also investigate the autocorrelation to ensure white noise residuals. Correlation between the factors has also been investigated to ensure absence of collinearity that could weaken the individual impact of these factors. Our final model consists of the unexpected components of the return on FTSE, S\&P 500, UK stock exchange turnover, money supply, sterling/us dollar exchange rate, inflation, the term structure of interest rate and default risk factor. We find these factors to be priced. We contribute to the existing literature by having identified two new factors in the UK market: the UK stock exchange turnover and the S\&P 500.

The APT can be represented as:

$$
R_{i t}=E\left(R_{i t}\right)+\sum_{j=1}^{K} b_{i j} F_{j t}+\varepsilon_{i t}
$$

Where $R_{i t}$ is the industry return on the $i$ th industry in period $t,(i=1$ to 28 and $t=1$ to $T), F_{j t}$ are the 
factors and $b_{i j}$ are the sensitivities. $\varepsilon_{i t}$ is a random error, which satisfies:

$$
\begin{gathered}
E\left(\varepsilon_{i t}\right)=0, E\left(\varepsilon_{i t} \varepsilon_{j t}{ }^{\prime}\right)=\sigma_{i j}, t=t^{\prime} \\
E\left(\varepsilon_{i t} \varepsilon_{j t}{ }^{\prime}\right)=0, t \neq t^{\prime}
\end{gathered}
$$

A common fundamental principle of the APT is that for each time period there exist $K+1$ constants $\lambda_{0 t}$ and $\lambda_{t}=\left[\lambda_{1 t, \ldots,} \lambda_{K t}\right]^{\prime}$, not all zero, such that expected return is approximately given by:

$$
E\left(R_{i t}\right)=\lambda_{0 t}+\sum_{j=1}^{K} b_{i j} \lambda_{j t}
$$

The APT can be written as a multivariate regression model for a sample of $\mathrm{N}<\mathrm{n}$ assets (industries), by retaining the error assumption of (3) and substituting (4) into (1) to obtain a system of $\mathrm{N}$ nonlinear regressions over $\mathrm{T}$ time periods.

$$
R_{i t}=\lambda_{0 t}+\sum_{j=1}^{K} b_{i j} \lambda_{j t}+\sum_{j=1}^{K} b_{i j} F_{j t}+\varepsilon_{i t}
$$

The conditional APM uses the same eight factors but the betas are time-varying and conditioned (Ferson \& Harvey, 1991, 1993, 1999) on the following set of instrumental variables; the one-month Treasury bill rate, lagged one month, the dividend yield on FT all share price index, lagged one month, the term structure of interest rates, lagged one month, the return on FT all share price index, lagged one month.

Similar to the arbitrage pricing theory that does not state which are the factors that should be part of the APM, the choice of variables that can be used as instruments to proxy the information that investors use are also not determined by any theory. The choice of instrumental variables has been guided in this study by the principle that we want to include variables that investors use to set prices and make decisions. Furthermore our choice has been consistent with previous studies on predictability of stock returns. For example Campbell (1987) finds the term structure can predict monthly stock returns, similarly Campbell and Shiller (1988) for the dividend yield. The one month-treasury bill rate has also been found to have predictive ability by Fama and Schwert (1977), Ferson (1989).

\section{Arbitrage Pricing Model Prices of Risk Estimation}

The estimation of the industry cost of equity capital requires in addition to the estimation of the betas, the estimation of the prices of risk. We estimate the prices of risk for both the unconditional and conditional APM and the CAPM, using NLSUR. This is one of the contributions of this paper in the estimation of the industry cost equity capital, since earlier studies have utilised as estimates of prices of risk either averages or estimates of cross-sectional regressions.

We estimate the prices of risk using this approach because since the same parameters appear in more than one of the regression equations, the system would be subject to cross-equation restrictions. In the presence of such restrictions, it is obvious that estimating all equations as a system rather than individually, provides more efficient estimates. The essential feature of simultaneous equation models is that two or more endogenous variables are determined jointly within the model, as a function of exogenous variables or predetermined variables and error terms.

The NLSUR model consists of a series of equations linked because the error terms across equations are correlated; the NLSUR model involves generalised least squares estimation and achieves an improvement in efficiency by taking into account (and allowing) for the fact that cross-equation error correlation may not be zero.

We can re-write Equation (5) by substituting the eight factors as following:

$$
\begin{aligned}
& R_{\text {INDUSTRYit }}=\lambda_{0}+\lambda_{1} b_{i 1}+\lambda_{2} b_{i 2}+\lambda_{3} b_{i 3}+\lambda_{4} b_{i 4}+\lambda_{5} b_{i 5}+\lambda_{6} b_{i 6}+\lambda_{7} b_{i 7}+\lambda_{8} b_{i 8}+ \\
& b_{i 1} F T_{t}+b_{i 2} S P_{t}+b_{i 3} T U_{t}+b_{i 4} M O_{t}+b_{i 5} E X C_{t}+b_{i 6} T E R M_{t}+b_{i 7} D E F_{t} b_{i 7}+b_{i 8} I N F L_{t}+e_{i t}
\end{aligned}
$$

Where: $R_{\text {INDUSTRYit }}=$ the industry return $i$ in month $t$.

Similar to Equation (5), $b_{i j}$ is the sensitivity of the industry return $i$ to factor $j(\mathrm{j}=1, \ldots, 8$ th factor, in our case). $\lambda_{j}=$ the price of risk for the factor $j(\mathrm{j}=1, \ldots, 8$ th factor $)$.

Where: $F T_{t}, S P_{t}, T U_{t}, M O_{t}, E X C_{t}, T E R M_{t}, D E F_{t}, I N F L_{t}$ are respectively the unanticipated return of FTSE, S\&P 500, UK stock exchange turnover, money supply, sterling/us dollar exchange rate, the term structure, default risk 
and inflation; $e_{i t}$ is the zero mean idiosyncratic term. In this specification, the price of risk $\left(\lambda_{\mathrm{j}}\right)$ of each factor is the same for all industries. Table 2 also shows explanation of the factors' symbols.

Table 4, Panel A shows the estimates, standard errors and t-statistics of the prices of risk of the FTSE, S\&P 500, UK stock exchange turnover, money supply, sterling/us dollar exchange rate, term structure, default risk and inflation. The table also shows that these are all statistically significant for the industry sectors. The factors that we find statistically significant in affecting industry returns during the 1993-March 2014 period affect firm and industry value by either affecting the discount rate or earnings stream. Discount rates should be affected by debt yield/return factors. We find the term structure of interest rates (the spread between 20 year government bonds and one month treasury bill rate) statistically significant. This makes sense since changes in yields are reflected in returns on assets. Other factors that we find to be statistically significant by affecting the discount rate is our "default risk"; proxied by the spread between 10 year swap rate and 20 year government bonds and the inflation factor.

Table 4. Estimation of prices of risk

Table 4 Panel A. Estimation of prices of risk for the entire period (time period 1993-March 2014)

\begin{tabular}{lllll}
\hline Price of Risk $(\lambda)$ & of factor & Coefficient & Standard Error & t-statistic \\
\hline$\lambda_{0}$ & CONSTANT & 0.087 & 0.017 & 0.517 \\
$\lambda_{1}$ & FTSE & 0.006 & 0.002 & $3.153^{* * *}$ \\
$\lambda_{2}$ & SP & 0.023 & 0.004 & $6.324^{* * *}$ \\
$\lambda_{3}$ & TURN & 0.220 & 0.037 & $5.981^{* * *}$ \\
$\lambda_{4}$ & MO & 0.003 & 0.000 & $5.856^{* * *}$ \\
$\lambda_{5}$ & EX & -0.017 & 0.003 & $-6.207^{* * *}$ \\
$\lambda_{6}$ & TERM & -0.173 & 0.033 & $-5.255^{* * *}$ \\
$\lambda_{7}$ & DEF & 0.035 & 0.009 & $3.991^{* * *}$ \\
$\lambda_{8}$ & INFL & -0.176 & 0.034 & $-5.164^{* * *}$ \\
\hline
\end{tabular}

Note. Panel A shows that all factors are statistically significant during the full period.

*** significant at $1 \%$ confidence level.

We find that inflation carries negative risk premium that is statistically significant. This suggests that UK industry assets/returns were acting as a hedge against the adverse impact of inflation on other assets that "may be relatively more fixed in nominal terms". This has also been suggested by Chen Roll and Ross (CRR), (1986), who find a negative sign for their inflation factors. Industries with lower inflation exposures required higher expected return.

The term structure of interest rates is statistically significant with a negative sign in our model. This may imply that industries whose returns are inversely related to increases in long rates over short rates are more valuable. CRR (1986) also find a negative sign for the term structure of interest rates. When long term real rates decrease, there is a lower real return on capital. Thus to protect against this happening, someone would place higher value on assets whose price goes up when long term real rates go down and subsequently these assets will carry negative risk premiums.

We also find that our "default risk" factor has a positive sign and is statistically significant, implying that investors would want to hedge against unexpected increases in the default risk premium due to increases in uncertainty in the markets. CRR (1986) also find a positive sign for a similar factor (difference between low grade and long term government bonds), that is significant on most of their sub-periods tested.

A variable that can influence returns through affecting expectations about future cash flows (other than inflation, etc.) is our exchange rate factor, proxied by the sterling/us dollar exchange rate. An increase in this variable implies that the purchasing power of sterling has increased. When sterling strengthens it negatively affects exports but improves imports. The UK economy is very international; the fact that we find the exchange factor statistically significant is consistent with this and in our model the UK currency has a systematic influence on industry returns.

We find the S\&P 500 factor to be statistically significant in UK. These two factors suggest that UK industry 
returns are affected by the US stock market and the value of sterling in relation to the dollar; which is what we have seen in practise throughout time.

A theoretical foundation for the signs of the factors has not been developed. A review of the literature in asset pricing shows that in some cases different researchers find different signs for the same factor/proxy. A possible explanation for this, which is not in the scope of this paper, is the use of different data sets.

We also split the data into two periods prior to the 2007 financial crisis (1993-2006) and the beginning and post the 2007 financial crisis (2007-March 2014). Table 4 Panel B shows the estimates, standard errors and t-statistics of the prices of risk of the FTSE, S\&P 500, UK stock exchange turnover, money supply, sterling/us dollar exchange rate, term structure, default risk and inflation during 1993-2006. All factors are statistically significant for the industry sectors with the exception of money supply that becomes less significant with a t-statistic of 1.4.

Table 4 Panel B. Estimation of prices of risk before the 2007 crisis (time period 1993-2006)

\begin{tabular}{lllll}
\hline Price of Risk $(\lambda)$ & of factor & Estimate & Standard Error & t-statistic \\
\hline$\lambda_{0}$ & CONSTANT & 0.003 & 0.292 & 0.009 \\
$\lambda_{1}$ & FTSE & 0.009 & 0.003 & $2.920^{* * *}$ \\
$\lambda_{2}$ & SP & 0.016 & 0.004 & $4.423^{* * *}$ \\
$\lambda_{3}$ & TURN & 0.240 & 0.046 & $5.219^{* * *}$ \\
$\lambda_{4}$ & MO & 0.001 & 0.000 & 1.404 \\
$\lambda_{5}$ & EX & -0.008 & 0.002 & $-3.678^{* * *}$ \\
$\lambda_{6}$ & TERM & -0.085 & 0.033 & $-2.560^{* * *}$ \\
$\lambda_{7}$ & DEF & 0.068 & 0.012 & $5.518^{* * * *}$ \\
$\lambda_{8}$ & INFL & -0.200 & 0.027 & $-7.353^{* * *}$ \\
\hline
\end{tabular}

Note. Panel B shows that all factors are statistically significant before the 2007 financial crisis, apart from the MO factor which becomes less significant.

*** significant at $1 \%$ confidence level.

Table 4 Panel C shows the estimates, standard errors and t-statistics of the prices of risk of the FTSE, S\&P 500, UK stock exchange turnover, money supply, sterling/us dollar exchange rate, term structure, default risk and inflation during the other sub-period 2007-March 2014. During this sub-period all the factors remain statistically significant with the only exception of the money supply factor that becomes insignificant. We note that during the 2007-March 2014 sub-period the default risk and inflation factors are the most significant, which makes sense given the fact during this time period we have had major corporate and sovereign defaults; and inflation is always a factor to be watched during and post a financial crisis.

Table 4 Panel C. Estimation of prices of risk post the 2007 crisis (time period 2007-March 2014)

\begin{tabular}{lllll}
\hline Price of Risk $(\lambda)$ & of factor & Estimate & Standard Error & t-statistic \\
\hline$\lambda_{0}$ & CONSTANT & 0.0369 & 0.0282 & 0.1310 \\
$\lambda_{1}$ & FTSE & 0.0052 & 0.0030 & $1.7536^{*}$ \\
$\lambda_{2}$ & SP & 0.0171 & 0.0039 & 4.4476 \\
$\lambda_{3}$ & TURN & 0.2650 & 0.0483 & $5.4841^{* * *}$ \\
$\lambda_{4}$ & MO & 0.0003 & 0.0004 & 0.7191 \\
$\lambda_{5}$ & EX & -0.0136 & 0.0025 & $-5.4890^{* * *}$ \\
$\lambda_{6}$ & TERM & -0.1123 & 0.0363 & $-3.0957^{* * *}$ \\
$\lambda_{7}$ & DEF & 0.0848 & 0.0132 & $6.4042^{* * *}$ \\
$\lambda_{8}$ & INFL & -0.1862 & 0.0237 & $-7.8425^{* * *}$ \\
\hline
\end{tabular}

Note. Panel C shows that all factors are statistically significant during and after the 2007 financial crisis, apart from the MO factor which becomes insignificant.

$* * *$ significant at $1 \%, * * 5 \%, * 10 \%$ confidence level. 
We find additional factors to the ones found significant by Chen Roll and Ross (CRR) (1986). Poon and Taylor (1991), also suggest that probably other macroeconomic factors except from the CRR (1986) are at work in the UK market. Our findings are not inconsistent with previous findings in the UK market. Antoniou, Garrett and Priestley (1998) find unexpected inflation, money supply and the market portfolio to be significant for 138 securities traded on the London Stock exchange, from January 1980 to August 1993. Antoniou, Garrett and Priestley (1998) in another study assessing the impact of exchange rate mechanism find inflation, money supply, default risk, exchange rate and to a lesser extent the market portfolio significant for 69 companies from 1989 to 1993. Clare Priestley and Thomas (1997) also find a proxy for unexpected inflation, the market portfolio and default risk to be priced for 15 stocks from 1978 to 1990.

\section{Conditional and Unconditional Betas Estimation}

Having identified our set of statistically significant macroeconomic factors using NLSUR described and discussed in section 3 and 4, we estimate 1) unconditional-constant betas and (2) conditional time varying betas for our factors.

In order to estimate the cost of equity capital as precise as possible we need precise estimates of exposure coefficients for each of the factors. Estimates of the APM would be precise, provided that betas are constant over time, however there is evidence that these vary over time. In order to examine this issue, we estimate full-period constant-unconditional and time varying conditional betas.

\subsection{Unconditional-Constant Betas Estimation}

The constant-unconditional betas are the slopes of the regression of the individual industry return on the factors throughout the period. During this period (1993-March 2014) the betas are assumed to be constant.

$$
\begin{aligned}
& R_{\text {INDUSTRYit }}=\alpha_{i}+b_{F T} F T_{t}+b_{S P} S P_{t}+b_{T U} T U_{t}+b_{M O} M O_{t}+b_{E X C} E X C_{t}+ \\
& b_{T E R M} T E R M_{t}+b_{D E F} D E F_{t}+b_{I N F L} I N F L_{t}+e_{i t}
\end{aligned}
$$

Consistent with the previous equations, $R_{\text {INDUSTRYit }}$ is the industry return $i$ in month ${ }_{t} ; \alpha_{i}$ a constant term; $b_{F T}, b_{S P}, b_{T U}, b_{M O}, b_{E X C}, b_{T E R M}, b_{D E F}, b_{I N F L}$ are the betas of the return on FTSE, S\&P 500, UK stock exchange turnover, money supply, sterling/us dollar exchange rate, term structure, default risk and inflation (i.e. $b_{i j}$ the sensitivity of the industry return $i$ to factor $j$ ), $e_{i t}$ is the zero mean error term.

The betas measure the average response of each industry to unanticipated changes in the respective economic factors. Some industries have negative betas and tend to do worse than expected when a factor is greater than expected. We find that in the constant beta model individual regressions of each industry onto the factors, for some industries some factors are more significant than others and the sign of some factors varies from positive to negative. This is not surprising as each industry has different sensitivity to different factors (Note 2).

Table 5 shows the adjusted R-squared of the regression of each industry return on the factors (to obtain the unconditional-constant betas). The results indicate that the predictive ability of the constant beta model varies from industry to industry. The average adjusted R-squared is approximately $43 \%$. The tobacco industry has lowest adjusted R-squared of approximately $12 \%$, however as Table 1 shows there are only 2 firms included in the tobacco index. The equity investment industry has the highest adjusted R-squared of $84.3 \%$, as Table 1 shows there are 177 firms included in this index. Elton, Gruber and Mei (1994) report adjusted R-squared in the range of $16 \%$ to $40 \%$ of the regressions to obtain the betas of their APM.

Table 5. Unconditional-constant betas regression adjusted r-squared

\begin{tabular}{llc}
\hline Symbol & Industry & Adjusted R-squared \\
\hline BANK & FTSE ASX Banks Index & $67.54 \%$ \\
MNG & FTSE ASX Mining Index & $48.78 \%$ \\
PHRM & FTSE ASX Pharmaceuticals \& Biotechnology & $20.26 \%$ \\
SUPP & FTSE ASX Support Services Index & $59.95 \%$ \\
LIFE & FTSE ASX Life Insurance Index & $58.34 \%$ \\
TOBC & FTSE ASX Tobacco Index & $11.76 \%$ \\
BEVG & FTSE ASX Beverages Index & $32.09 \%$ \\
LEIS & FTSE ASX Travel Leisure Index & $57.85 \%$ \\
INVC & FTSE ASX Investment Instruments & $84.27 \%$ \\
MEDA & FTSE ASX Media Index & $56.36 \%$ \\
\hline
\end{tabular}




\begin{tabular}{llc}
\hline FOOD & FTSE ASX Food Producers Index & $28.78 \%$ \\
OTHR & FTSE ASX Fin Services Index & $65.14 \%$ \\
RETG & FTSE ASX Gen Retailers Index & $41.71 \%$ \\
AERO & FTSE ASX Aerospace \& Defence & $45.54 \%$ \\
FDRT & FTSE ASX Food Drug Retailers Index & $18.65 \%$ \\
TELE & FTSE ASX Fixed Line Telecommunications & $36.92 \%$ \\
INSU & FTSE ASX Nonlife Insurance Index & $42.75 \%$ \\
ENGN & FTSE ASX Industrial Engineering Index & $57.04 \%$ \\
CONS & FTSE ASX Construct Material Index & $48.51 \%$ \\
INFT & FTSE ASX Tech Hardware Index & $24.72 \%$ \\
CHEM & FTSE ASX Chemicals Index & $49.51 \%$ \\
SOFT & FTSE ASX Software \& Computer Service & $38.34 \%$ \\
ELTR & FTSE ASX Electronic \& Electrical Equipment & $41.62 \%$ \\
HLTH & FTSE ASX Health Care Equipment and Services & $24.40 \%$ \\
PERC & FTSE ASX Personal Goods Index & $24.63 \%$ \\
AUTO & FTSE ASX Automobiles Parts Index & $40.80 \%$ \\
TRAN & FTSE ASX Industrial Transportation Index & $52.63 \%$ \\
HOUS & FTSE ASX Leisure Goods Index & $15.25 \%$ \\
AVERAGE & & $42.65 \%$ \\
\hline
\end{tabular}

\subsection{Conditional Betas Estimation}

Conditional betas, defined in this paper, incorporate not only time variation as a property, but also these betas are conditioned to a set of information-instrumental variables, which reflect information in the market that investors use.

Conditional beta estimation involves the following steps. Step 1, the estimation of rolling betas. Step 2, the use of these rolling betas as dependent variable regressed on a set of instrumental variables. The fitted values from this regression (the beta regressed on the instrumental variables) are defined as the conditional beta. Thus, in the first step we incorporate the time variation property in the estimation of the conditional betas. The second step incorporates the conditional property, since the time-varying betas are conditioned on a set of instrumental variables that convey publicly available information.

Step 1: In order to document temporal variation in betas, we estimate rolling regressions using five years of past returns, i.e., using a rolling window of 60 prior monthly returns. Thus the industry's exposure to the macroeconomic factors and the market index are estimated by regressing the industry return on the unanticipated components of the factors, using time series regressions over an estimation period of 5 years, i.e., (60 months rolling). The slope coefficients in the time-series regressions provide estimates of the betas. We use the five-year period and update the estimates annually. For example, we run the following regression with the industry return being the dependent variable on the factors, from 1993-1997 in order to obtain betas for 1998.

$$
\begin{aligned}
& R_{\text {INDUSTRYit }}=\alpha_{i}+b_{F T} F T_{t}+b_{S P} S P_{t}+b_{T U} T U_{t}+b_{M O} M O_{t}+b_{E X C} E X C_{t}+ \\
& b_{\text {TERM }} \text { TERM }_{t}+b_{D E F} D E F_{t}+b_{I N F L} I N F L_{t}+e_{i t}
\end{aligned}
$$

Consistent with the previous equations, $R_{\text {INDUSTRYit }}$ is the industry return $i$ in month $t ; \alpha_{i}$ a constant term; $b_{F T}, b_{S P}, b_{T U}, b_{M O}, b_{E X C}, b_{T E R M}, b_{D E F}, b_{I N F L}$ are the betas of the return on unexpected FTSE, S\&P 500, UK stock exchange turnover, money supply, sterling/us dollar exchange rate, term structure, default risk and inflation (i.e. $b_{i j}$ the sensitivity of the industry return $i$ to factor $j$ ), $e_{i t}$ is the zero mean error term.

Thus the outcome of step 1 is a time-series (from 1998 to March 2014) of rolling betas for each factor. In step 2, each beta is used as dependent variable regressed on a constant and a set of instrumental variables. The fitted values from this regression are defined as the conditional betas. A conditional beta is defined as the beta conditioned on a set of instrumental variables.

Hence having obtained a time series of rolling betas from 1998 to March 2014 for the return on FTSE, S\&P 500, UK stock exchange turnover, money supply, sterling/us dollar exchange rate, term structure, default risk and inflation, we use the following model and run it for each factor $J$.

$$
b_{j t}=\delta_{0}+\delta_{1} I T B 1_{t-1}+\delta_{2} I D I V_{t-1}+\delta_{3} I T S_{t-1}+\delta_{4} I F T_{t-1}+e_{t}
$$


Where $b_{j t}$ represents the beta/sensitivity associated with each factor $j, e_{t}$ is the residual, $\delta_{0}$ is a constant and $\delta_{1}$ to $\delta_{4}$ are the coefficients of the instrumental variables ITB1 $1_{t-1}, I D I V_{t-1}, I T S_{t-1}, I F T_{t-1}$; the one month Treasury bill rate, lagged one month, the dividend yield on FT all share price index, lagged one month, the term structure of interest rates, lagged one month and the return on FT all share price index, lagged one month. These instrumental variables are chosen because they summarise expectations in the economy that are related to the prospects for stock returns, that is they have the ability to forecast asset returns. Short-term interest rates, for example, have been prominent instruments in several studies (Note 3); their importance as instruments in tests of asset pricing models stems from their relation with consumption, production and returns. The dividend yield has also been examined and found to have predictive ability (Note 4).

To forecast the conditional betas we estimate conditional betas with an out-of-sample evaluation. We fit a model in which the rolling beta is used as dependent variable regressed on a constant and a set of instrumental variables. We use a holdout sample of 132 months where the out-of-sample evaluation is taking place. Using an initial estimation period of 60 months from 1998-2002, we forecast the conditional betas for the next twelve months, January-December 2003. Then the next twelve months are added to the estimation period to forecast the conditional betas for the following twelve months, January-December 2004 (Note 5). The most statistically significant instrumental variables (at the $1 \%$ level) are the term structure of interest rates lagged one month $\left(I T S_{t-1}\right)$ and dividend yield on FT all share price index lagged one month $\left(I D I V_{t-1}\right)$. This is not surprising since the tem structure of interest rates is very important in assessing overall economic growth and dividend yields are a component of stock returns.

Table 6 reports the Adjusted R-squared of the regression of the rolling beta of each factor (FTSE, S\&P 500, UK stock exchange turnover, money supply, sterling/us dollar exchange rate, term structure, default risk and inflation) used as dependent variable regressed on the instrumental variables for year 2013, for every industry and averages. Due to vast amount of output from running conditional regressions we present results for 2013. All the results can be provided upon request.

Table 6. Conditional betas regression adjusted r-squared

\begin{tabular}{lclllllllc}
\hline Industry/beta & $b_{F T}$ & $b_{S P}$ & $b_{T U}$ & $b_{M O}$ & $b_{E X C}$ & $b_{T E R M}$ & $b_{D E F}$ & $b_{I N F L}$ & $\begin{array}{c}\text { AVERAGE adj. R2 } \\
\text { for each industry }\end{array}$ \\
\hline BANK & $35.09 \%$ & $68.16 \%$ & $87.03 \%$ & $38.65 \%$ & $47.49 \%$ & $80.25 \%$ & $69.64 \%$ & $35.38 \%$ & $57.71 \%$ \\
MNG & $62.61 \%$ & $31.87 \%$ & $2.65 \%$ & $3.69 \%$ & $66.37 \%$ & $23.41 \%$ & $66.70 \%$ & $40.00 \%$ & $37.16 \%$ \\
PHRM & $4.33 \%$ & $21.83 \%$ & $2.48 \%$ & $65.04 \%$ & $64.79 \%$ & $65.03 \%$ & $22.96 \%$ & $67.62 \%$ & $39.26 \%$ \\
SUPP & $51.82 \%$ & $62.06 \%$ & $58.80 \%$ & $82.03 \%$ & $23.30 \%$ & $15.54 \%$ & $80.42 \%$ & $63.78 \%$ & $54.72 \%$ \\
LIFE & $47.03 \%$ & $33.04 \%$ & $47.74 \%$ & $46.43 \%$ & $20.04 \%$ & $42.59 \%$ & $80.13 \%$ & $71.86 \%$ & $48.61 \%$ \\
TOBC & $61.27 \%$ & $42.25 \%$ & $43.25 \%$ & $78.97 \%$ & $39.94 \%$ & $76.80 \%$ & $38.77 \%$ & $14.00 \%$ & $49.41 \%$ \\
BEVG & $32.28 \%$ & $40.42 \%$ & $58.97 \%$ & $67.13 \%$ & $43.72 \%$ & $67.17 \%$ & $54.17 \%$ & $81.33 \%$ & $55.65 \%$ \\
LEIS & $6.82 \%$ & $16.23 \%$ & $62.29 \%$ & $78.28 \%$ & $23.36 \%$ & $82.51 \%$ & $86.93 \%$ & $4.43 \%$ & $45.11 \%$ \\
INVC & $81.07 \%$ & $22.09 \%$ & $85.71 \%$ & $48.51 \%$ & $56.51 \%$ & $70.85 \%$ & $72.06 \%$ & $43.38 \%$ & $60.02 \%$ \\
MEDA & $44.20 \%$ & $52.53 \%$ & $85.07 \%$ & $64.78 \%$ & $8.14 \%$ & $81.37 \%$ & $83.86 \%$ & $24.49 \%$ & $55.55 \%$ \\
FOOD & $70.16 \%$ & $71.59 \%$ & $63.11 \%$ & $80.37 \%$ & $52.98 \%$ & $66.97 \%$ & $28.80 \%$ & $71.23 \%$ & $63.15 \%$ \\
OTHR & $74.10 \%$ & $36.58 \%$ & $85.10 \%$ & $15.53 \%$ & $2.98 \%$ & $35.90 \%$ & $41.83 \%$ & $34.93 \%$ & $40.87 \%$ \\
RETG & $78.38 \%$ & $78.15 \%$ & $60.67 \%$ & $30.47 \%$ & $73.06 \%$ & $86.21 \%$ & $62.90 \%$ & $3.07 \%$ & $59.11 \%$ \\
AERO & $30.46 \%$ & $6.05 \%$ & $58.09 \%$ & $79.39 \%$ & $37.26 \%$ & $45.57 \%$ & $72.30 \%$ & $35.62 \%$ & $45.59 \%$ \\
FDRT & $65.67 \%$ & $61.82 \%$ & $69.36 \%$ & $32.21 \%$ & $55.88 \%$ & $51.77 \%$ & $67.59 \%$ & $7.75 \%$ & $51.51 \%$ \\
TELE & $14.82 \%$ & $20.24 \%$ & $51.39 \%$ & $78.99 \%$ & $26.44 \%$ & $56.63 \%$ & $5.21 \%$ & $41.34 \%$ & $36.88 \%$ \\
INSU & $66.07 \%$ & $45.35 \%$ & $57.89 \%$ & $8.09 \%$ & $18.03 \%$ & $82.55 \%$ & $48.72 \%$ & $75.57 \%$ & $50.28 \%$ \\
ENGN & $42.04 \%$ & $48.01 \%$ & $42.84 \%$ & $45.13 \%$ & $73.99 \%$ & $51.26 \%$ & $83.51 \%$ & $78.26 \%$ & $58.13 \%$ \\
CONS & $37.61 \%$ & $45.11 \%$ & $39.86 \%$ & $84.92 \%$ & $62.62 \%$ & $79.37 \%$ & $74.51 \%$ & $40.19 \%$ & $58.02 \%$ \\
INFT & $54.95 \%$ & $20.29 \%$ & $44.48 \%$ & $72.24 \%$ & $9.30 \%$ & $29.69 \%$ & $48.84 \%$ & $52.07 \%$ & $41.48 \%$ \\
\hline
\end{tabular}




\begin{tabular}{|c|c|c|c|c|c|c|c|c|c|}
\hline CHEM & $24.84 \%$ & $29.51 \%$ & $61.41 \%$ & $66.25 \%$ & $54.92 \%$ & $86.12 \%$ & $57.59 \%$ & $64.71 \%$ & $55.67 \%$ \\
\hline SOFT & $70.97 \%$ & $29.44 \%$ & $86.45 \%$ & $70.58 \%$ & $27.24 \%$ & $79.10 \%$ & $42.32 \%$ & $55.20 \%$ & $57.66 \%$ \\
\hline ELTR & $58.78 \%$ & $60.04 \%$ & $86.75 \%$ & $12.97 \%$ & $36.21 \%$ & $41.25 \%$ & $72.80 \%$ & $45.16 \%$ & $51.74 \%$ \\
\hline HLTH & $70.21 \%$ & $63.94 \%$ & $45.06 \%$ & $9.51 \%$ & $16.76 \%$ & $55.82 \%$ & $79.29 \%$ & $21.50 \%$ & $45.26 \%$ \\
\hline PERC & $69.40 \%$ & $65.82 \%$ & $85.79 \%$ & $86.62 \%$ & $7.14 \%$ & $60.24 \%$ & $62.63 \%$ & $66.15 \%$ & $62.97 \%$ \\
\hline AUTO & $35.23 \%$ & $27.03 \%$ & $3.26 \%$ & $64.06 \%$ & $35.35 \%$ & $64.47 \%$ & $75.02 \%$ & $52.88 \%$ & $44.66 \%$ \\
\hline TRAN & $53.10 \%$ & $27.07 \%$ & $34.21 \%$ & $60.28 \%$ & $38.39 \%$ & $56.16 \%$ & $39.61 \%$ & $14.92 \%$ & $40.47 \%$ \\
\hline HOUS & $42.37 \%$ & $55.32 \%$ & $68.65 \%$ & $63.92 \%$ & $57.62 \%$ & $27.90 \%$ & $66.70 \%$ & $33.91 \%$ & $52.05 \%$ \\
\hline \multicolumn{10}{|c|}{ AVERAGE adj. R2 } \\
\hline for each beta & $49.49 \%$ & $42.21 \%$ & $56.37 \%$ & $54.82 \%$ & $38.57 \%$ & $59.38 \%$ & $60.21 \%$ & $44.31 \%$ & \\
\hline
\end{tabular}

For example Table 6, row 1, reports that for the banking industry (BANK) the rolling beta $\left(b_{T U}\right)$ of the stock exchange turnover when regressed on the instrumental variables, has the highest adjusted R squared of $87.03 \%$, amongst the other rolling betas within that industry.

Looking at each element of the last column we see the average predictive ability of the conditional regressions of all factors' rolling betas per industry (average adjusted R-squared for all rolling betas $b_{F T}, b_{S P}, b_{T U}, b_{M O}, b_{E X C}, b_{T E R M}$, $b_{D E F}, b_{I N F L}$ ) for each industry; the highest adjusted R-squared is $63.15 \%$ for the food industry (FOOD) and the lowest is $37.12 \%$ for the mining industry (MNG). Ferson and Harvey (1991) report adjusted R-squared for the conditional regressions (i.e. 5 year rolling beta on the lagged instruments) in the range of $20 \%$.

Looking at Table 6, bottom row per column, we see the average adjusted R-squared for all the industries per beta (of the regression of the rolling betas of each factor regressed on a constant and the set of instrumental variables). This average adjusted R-squared varies from the highest adjusted R-squared of $60.21 \%$ for the rolling beta $\left(b_{D E F}\right)$ of the default risk factor to the lowest of $42.21 \%$ for the rolling beta $\left(b_{S P}\right)$ of the S\&P factor.

\section{The CAPM}

We obtain CAPM estimates of the UK industry cost of equity capital for the full-period (1993-March 2014). Using NLSUR we obtain an estimate of the market portfolio price of risk that is equal across every industry and different market betas for each industry.

Table 7 shows the market beta estimates for each industry based on the CAPM. The standard error and t-statistic are also reported.

Table 7. Market beta

\begin{tabular}{llccc}
\hline Symbol & Industry & Market Beta & Standard Error & t-statistic \\
\hline BANK & FTSE ASX Banks Index & 1.02 & 0.033 & 30.464 \\
MNG & FTSE ASX Mining Index & 1.10 & 0.049 & 22.481 \\
PHRM & FTSE ASX Pharmaceuticals \& Biotechnology & 0.88 & 0.036 & 24.455 \\
SUPP & FTSE ASX Support Services Index & 1.01 & 0.024 & 41.543 \\
LIFE & FTSE ASX Life Insurance Index & 1.06 & 0.037 & 28.448 \\
TOBC & FTSE ASX Tobacco Index & 0.89 & 0.046 & 19.212 \\
BEVG & FTSE ASX Beverages Index & 0.94 & 0.031 & 30.643 \\
LEIS & FTSE ASX Travel Leisure Index & 1.02 & 0.026 & 38.837 \\
INVC & FTSE ASX Investment Instruments & 1.02 & 0.015 & 68.292 \\
MEDA & FTSE ASX Media Index & 1.08 & 0.031 & 34.877 \\
FOOD & FTSE ASX Food Producers Index & 0.94 & 0.031 & 29.971 \\
OTHR & FTSE ASX Fin Services Index & 1.02 & 0.032 & 31.812 \\
RETG & FTSE ASX Gen Retailers Index & 1.09 & 0.032 & 34.374 \\
AERO & FTSE ASX Aerospace \& Defence & 0.99 & 0.035 & 28.120 \\
FDRT & FTSE ASX Food Drug Retailers Index & 0.87 & 0.037 & 23.421 \\
TELE & FTSE ASX Fixed Line Telecommunications & 1.01 & 0.044 & 23.114 \\
INSU & FTSE ASX Nonlife Insurance Index & 1.07 & 0.037 & 29.120 \\
\hline
\end{tabular}




\begin{tabular}{lllll}
\hline ENGN & FTSE ASX Industrial Engineering Index & 1.05 & 0.034 & 30.312 \\
CONS & FTSE ASX Construct Material Index & 1.05 & 0.034 & 30.902 \\
INFT & FTSE ASX Tech Hardware Index & 1.19 & 0.084 & 14.051 \\
CHEM & FTSE ASX Chemicals Index & 0.98 & 0.034 & 28.926 \\
SOFT & FTSE ASX Software \& Computer Service & 1.12 & 0.054 & 20.622 \\
ELTR & FTSE ASX Electronic \& Electrical Equipment & 1.04 & 0.060 & 17.397 \\
HLTH & FTSE ASX Health Care Equipment and Services & 0.91 & 0.037 & 24.843 \\
PERC & FTSE ASX Personal Goods Index & 0.94 & 0.045 & 20.996 \\
AUTO & FTSE ASX Automobiles Parts Index & 0.97 & 0.057 & 16.966 \\
TRAN & FTSE ASX Industrial Transportation Index & 0.99 & 0.029 & 33.457 \\
HOUS & FTSE ASX Leisure Goods Index & 1.04 & 0.055 & 18.844 \\
\hline
\end{tabular}

The market betas are statistically significant for all industries. We find, for example, the banking sector to have a beta of 1.02 , life insurance of 1.06 , the pharmaceuticals 0.88 , tobacco 0.89 , beverages 0.94 , food producers 0.94 , general retailers 1.09. Fama and French (1997) find broadly similar betas for similar industry indices in the US market. They report the following betas: for the banking sector 1.09, pharmaceuticals 0.92 , insurance 1.01 , tobacco 0.8 , beverages 0.92 , food producers 0.87 , and general retailers. Bloomberg reports similar betas in the UK.

\section{Cost of Equity Capital}

Having estimated the prices of risk of our macroeconomic factor model; the constant betas for the unconditional APM; the conditional-time varying betas for the conditional APM; and the common CAPM, we incorporate these estimates to calculate the cost of equity capital.

Figure 1 shows the CAPM, unconditional-constant APM and conditional-time varying APM weighted average cost of equity capital for all industries. The weighted average cost of equity capital from 2003 until March 2014 estimated by the CAPM is $13.2 \%, 9.1 \%$ by the unconditional-constant APM and $10.1 \%$ by the conditional-time varying APM. The conditional-time varying APM varies from 5\%-6\% just before the 2007 crisis to over $16 \%$ post the crisis; starting to gradually increase just after the financial crisis. It seems that the conditional APM picks up the fact that high expected returns are required in recessions by investors to make up for the additional risk. Goldenberg and Robin (1991), find a cost of equity capital for their portfolio of US electric utilities of 17\% using macroeconomic factor APM, whereas with the statistical factor APM and the CAPM they find it to be at $15.35 \%$ and $11.56 \%$ respectively.

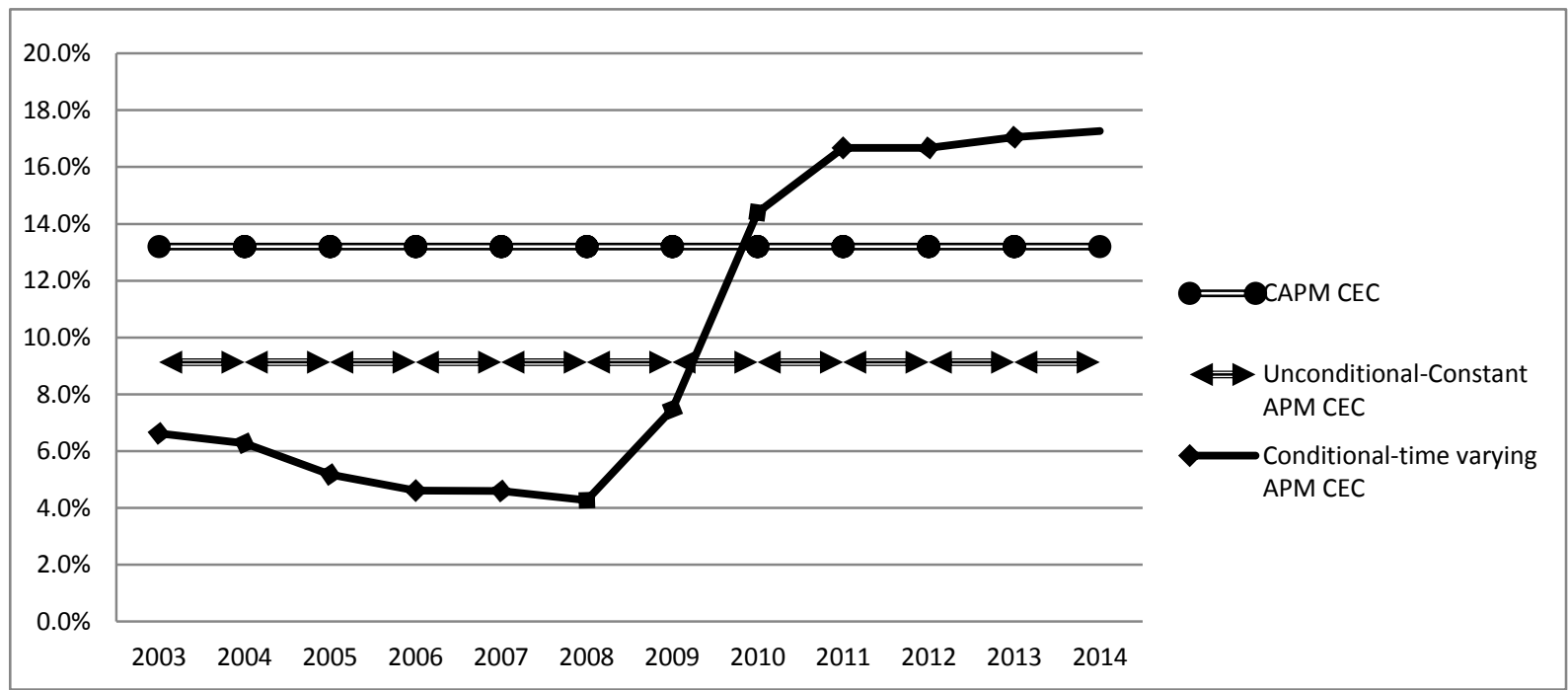

Figure 1. Industry Cost of Equity Capital (CEC)

Tables 8, 9, 10 and 11 show the errors of the cost of equity capital for each model and whether the difference in the errors between the competing models is statistically significant. In order to evaluate the comparative 
performance of the alternative models estimated, we use the Mean Square Error (MSE). In general, tests employed to compare performance of models are unique and no single test is superior to all others; all have advantages and disadvantages. In the literature and in practise the Mean Square Error (MSE) test has been frequently used. The MSE is a summary measure and provides for a quadratic loss function as it squares and subsequently averages the various errors.

$$
M S E=\sum_{t=1}^{n} \frac{e_{t}^{2}}{n-v}
$$

Where $e_{t}$ is the difference between the model's estimates and the actual industry returns, $n$ is the number of observations and $v$ the number of independent variables.

We report weighted average MSE for each model for i) our reduced full period (2003-March 2014) (the full period is reduced due to the fact that we lose some observations due to running conditional regressions for the conditional APM (Note 6) and (ii) during and after the 2007 financial crisis (2007 until March 2014). The objective is to investigate the performance of the models not only during our full sample time period but also during and post a financial crisis.

Table 8 shows the MSE for each industry and the weighted average MSE for the reduced full time period (2003-March 2014). The weighted average MSE for the unconditional, conditional beta APM and the CAPM is $0.009,0.0011$ and 0.024 respectively. We notice that the differences in the MSE between the two APMs are very small. So we test whether the difference between the MSE of the conditional and the unconditional APM is statistically significant with a t-test. Table 9 shows that the p-value of 0.315 is greater than the critical value of 0.05 , indicating that the difference in the MSE of the two APMs is statistically insignificant; implying that the errors of the two APMs are more or less the same. On the other hand when we test whether the difference between the CAPM MSE and the unconditional APM MSE is statistically significant, we find a p-value of 0.00, indicating that this difference in the MSE is statistically significant. The CAPM errors are higher and significantly different from the errors of the unconditional APM. Similarly we find a p-value of 0.00 , when we test the statistical significance of the difference in the CAPM MSE and the conditional APM MSE, showing that the difference in the MSE is statistically significant. The CAPM errors are higher and significantly different from the errors of the conditional APM. These results imply that during the full period it is not so important whether one uses the unconditional or the conditional APM as the difference in their MSEs is statistically insignificant. On the contrary the difference in the MSE of the CAPM with any of the APMs MSE is statistically significant. The MSE of the CAPM is higher compared to any of the APMs. The full period results imply that there is not so much difference in the errors of the cost of equity capital estimated between unconditional and conditional beta model as there is between the CAPM and the APM.

Our evidence that the APM is much better than the CAPM is consistent with US evidence. Pettway and Jordan (1987) in their comparison of the relative efficiency of the CAPM and APT, using weekly data on electric utilities, find that the APM provides better estimates of equity returns than the CAPM. However our study extends the existing literature by showing that both unconditional and conditional versions of the APM are better than the CAPM.

Table 8. Mean Square Error (MSE)-reduced full time period (2003-March 2014)

\begin{tabular}{llccc}
\hline Symbol & Industry & CAPM & APM-Unconditional & APM-Conditional \\
\hline BANK & FTSE ASX Banks Index & 0.0023 & 0.0012 & 0.0011 \\
MNG & FTSE ASX Mining Index & 0.0029 & 0.0016 & 0.0017 \\
PHRM & FTSE ASX Pharmaceuticals \& Biotechnology & 0.0019 & 0.0004 & 0.0005 \\
SUPP & FTSE ASX Support Services Index & 0.0021 & 0.0006 & 0.0006 \\
LIFE & FTSE ASX Life Insurance Index & 0.0028 & 0.0014 & 0.0016 \\
TOBC & FTSE ASX Tobacco Index & 0.0020 & 0.0004 & 0.0005 \\
BEVG & FTSE ASX Beverages Index & 0.0020 & 0.0004 & 0.0004 \\
LEIS & FTSE ASX Travel Leisure Index & 0.0021 & 0.0005 & 0.0007 \\
INVC & FTSE ASX Investment Instruments & 0.0020 & 0.0006 & 0.0007 \\
MEDA & FTSE ASX Media Index & 0.0024 & 0.0007 & 0.0007 \\
FOOD & FTSE ASX Food Producers Index & 0.0020 & 0.0004 & 0.0006 \\
OTHR & FTSE ASX Fin Services Index & 0.0021 & 0.0010 & 0.0010 \\
RETG & FTSE ASX Gen Retailers Index & 0.0027 & 0.0007 & 0.0007 \\
\hline
\end{tabular}




\begin{tabular}{lllll}
\hline AERO & FTSE ASX Aerospace \& Defence & 0.0022 & 0.0008 & 0.0011 \\
FDRT & FTSE ASX Food Drug Retailers Index & 0.0020 & 0.0005 & 0.0005 \\
TELE & FTSE ASX Fixed Line Telecommunications & 0.0026 & 0.0014 & 0.0014 \\
INSU & FTSE ASX Nonlife Insurance Index & 0.0025 & 0.0006 & 0.0008 \\
ENGN & FTSE ASX Industrial Engineering Index & 0.0024 & 0.0009 & 0.0014 \\
CONS & FTSE ASX Construct Material Index & 0.0024 & 0.0008 & 0.0012 \\
INFT & FTSE ASX Tech Hardware Index & 0.0037 & 0.0026 & 0.0049 \\
CHEM & FTSE ASX Chemicals Index & 0.0021 & 0.0008 & 0.0009 \\
SOFT & FTSE ASX Software \& Computer Service & 0.0028 & 0.0016 & 0.0017 \\
ELTR & FTSE ASX Electronic \& Electrical Equipment & 0.0028 & 0.0025 & 0.0035 \\
HLTH & FTSE ASX Health Care Equipment \& Services & 0.0022 & 0.0007 & 0.0008 \\
PERC & FTSE ASX Personal Goods Index & 0.0024 & 0.0011 & 0.0009 \\
AUTO & FTSE ASX Automobiles Parts Index & 0.0031 & 0.0026 & 0.0030 \\
TRAN & FTSE ASX Industrial Transportation Index & 0.0021 & 0.0007 & 0.0008 \\
HOUS & FTSE ASX Leisure Goods Index & 0.0035 & 0.0017 & 0.0019 \\
AVERAGE & & 0.0024 & 0.0009 & 0.0011 \\
\hline
\end{tabular}

Note. The period is reduced starting from 2003 as we lose observations by running conditional regressions for the conditional APM.

$M S E=\sum_{t=1}^{n} \frac{e_{t}^{2}}{n-v}$ Where $e_{t}$ is the difference between the model estimates and the actual industry returns, $n$ is the number of observations and $v$ the number of independent variables.

Table 9. MSE T-test-reduced full time period (2003-March 2014)

$\begin{aligned} & \text { p-value testing statistical significance of the difference in MSE of } \\ & \text { the Unconditional and Conditional APM }\end{aligned}$
$\begin{aligned} & \text { p-value testing statistical significance of the difference in MSE of } \\ & \text { the CAPM and Conditional APM }\end{aligned}$
$\begin{aligned} & \text { p-value testing statistical significance of the difference in } \\ & \text { the CAPM and Unconditional APM }\end{aligned}$

Table 10 shows the MSE for each industry and the weighted average MSE from 2007- March 2014 for all models. We also test the statistical significance of the difference in the MSEs between the competing models with a t-test in Table 11.

Table 10. Mean Square Error (MSE)-time period (2007-March 2014)

\begin{tabular}{llccc}
\hline MSE & Industry & CAPM & APT-Unconditional & APT-Conditional \\
\hline BANK & FTSE ASX Banks Index & 0.0030 & 0.0025 & 0.0013 \\
MNG & FTSE ASX Mining Index & 0.0039 & 0.0035 & 0.0021 \\
PHRM & FTSE ASX Pharm \& Biotech & 0.0026 & 0.0010 & 0.0004 \\
SUPP & FTSE ASX Support Srvcs & 0.0028 & 0.0013 & 0.0007 \\
LIFE & FTSE ASX Life Insurance & 0.0032 & 0.0028 & 0.0015 \\
TOBC & FTSE ASX Tobacco Index & 0.0029 & 0.0015 & 0.0004 \\
BEVG & FTSE ASX Beverages Index & 0.0028 & 0.0010 & 0.0004 \\
LEIS & FTSE ASX Travel Leisure & 0.0030 & 0.0014 & 0.0006 \\
INVC & FTSE ASX Eqy Invst Instr & 0.0026 & 0.0015 & 0.0008 \\
MEDA & FTSE ASX Media Index & 0.0031 & 0.0021 & 0.0008 \\
FOOD & FTSE ASX Food Producers & 0.0028 & 0.0010 & 0.0006 \\
OTHR & FTSE ASX Fin Services & 0.0027 & 0.0025 & 0.0013 \\
RETG & FTSE ASX Gen Retailers & 0.0038 & 0.0015 & 0.0008 \\
AERO & FTSE ASX Aero \& Defense & 0.0027 & 0.0018 & 0.0010 \\
FDRT & FTSE ASX Food Drug Retl & 0.0027 & 0.0011 & 0.0006 \\
TELE & FTSE ASX Fixed Line Tele & 0.0033 & 0.0035 & 0.0014 \\
INSU & FTSE ASX Nonlife Insur & 0.0031 & 0.0019 & 0.0008 \\
\hline
\end{tabular}




\begin{tabular}{|c|c|c|c|c|}
\hline ENGN & FTSE ASX Indust Engineer & 0.0031 & 0.0022 & 0.0015 \\
\hline CONS & FTSE ASX Construct Mater & 0.0034 & 0.0017 & 0.0012 \\
\hline INFT & FTSE ASX Tech Hardware & 0.0036 & 0.0096 & 0.0050 \\
\hline CHEM & FTSE ASX Chemicals Index & 0.0028 & 0.0018 & 0.0010 \\
\hline SOFT & FTSE ASX Sftwr Comp Srvs & 0.0030 & 0.0054 & 0.0013 \\
\hline ELTR & FTSE ASX Elect/Ele Equip & 0.0030 & 0.0068 & 0.0046 \\
\hline HLTH & FTSE ASX Health Care Eqp & 0.0029 & 0.0014 & 0.0008 \\
\hline PERC & FTSE ASX Personal Goods & 0.0035 & 0.0024 & 0.0012 \\
\hline AUTO & FTSE ASX Automobiles Prt & 0.0041 & 0.0051 & 0.0040 \\
\hline TRAN & FTSE ASX Indust Transprt & 0.0030 & 0.0015 & 0.0009 \\
\hline HOUS & FTSE ASX Leisure Goods & 0.0050 & 0.0033 & 0.0026 \\
\hline AVERAGE & & 0.0031 & 0.0023 & 0.0012 \\
\hline
\end{tabular}

Note. $M S E=\sum_{t=1}^{n} \frac{e_{t}^{2}}{n-v}$ Where $e_{t}$ is the difference between the model estimates and the actual industry returns, $n$ is the number of observations and $v$ the number of independent variables.

Table 11 shows that the p-value of 0.008 is lower than the critical value of 0.05 , indicating that the difference in the MSE of the unconditional and conditional APM is statistically significant. During and post the period of financial crisis the conditional APM with a MSE of 0.0012 provides more accurate estimates compared to the unconditional model (MSE 0.0023).

Table 11 reports a p-value of 0.172 when we test the difference in the errors between the unconditional APM and the CAPM from 2007 onwards. Indicating that the difference in the MSE between the CAPM and unconditional APM is statistically insignificant. Further the difference in the errors between the conditional APM and the CAPM is statistically significant with a p-value of 0.00 .

Table 11. MSE T-test time period (2007-March 2014)

\begin{tabular}{|c|c|c|}
\hline $\begin{array}{l}\text { p-value testing statistical significance of the difference in MSE } \\
\text { of the Unconditional and Conditional APM }\end{array}$ & 0.008 & $\begin{array}{l}\text { p-value }<0.05 \text {; the difference in the MSE is } \\
\text { statistically significant at the } 5 \% \text { level }\end{array}$ \\
\hline $\begin{array}{l}\text { p-value testing statistical significance of the difference in MSE } \\
\text { of the CAPM and Conditional APM }\end{array}$ & 0.000 & $\begin{array}{l}\mathrm{p} \text {-value }<0.05 \text {; the difference in the MSE is } \\
\text { statistically significant at the } 5 \% \text { level }\end{array}$ \\
\hline $\begin{array}{l}\text { p-value testing statistical significance of the difference in the } \\
\text { MSE of the CAPM and Unconditional APM }\end{array}$ & 0.172 & $\begin{array}{l}\text { p-value>0.05; the difference in the MSE is } \\
\text { statistically insignificant }\end{array}$ \\
\hline
\end{tabular}

During and post the financial crisis of 2007, we find that the conditional APM with a MSE of 0.0012 provides more accurate estimates compared to the unconditional APM (MSE 0.0023) and the CAPM (MSE 0.0031) for all industries. The conditional APM performs better from the models tested during the period of crisis. During the 2007 crisis there was a lot of volatility in the marketplace. In order to assess whether indeed the market volatility is a significant variable in the conditional cost of equity capital during 2007 to March 2014, we regress the conditional cost of equity capital on to a constant and the FTSE volatility index. We find the FTSE volatility index to be statistically significant at the $1 \%$ level with a t-statistic of 6.363 and a regression adjusted R-squared of $44 \%$.

During the period that the conditional APM performs best we have had major disruptions in financial markets. From 2007 we had major defaults in the mortgage market for subprime borrowers. Many banks and firms suffered losses of hundreds of billions. Credit became much harder to obtain and much more expensive. As a result lending declined, consumption and investment fell causing further sharp contraction in the economy. The uncertainty in the economy went on with major failures of high profile firms.

The economic repercussions of our results indicate that during the period of severe economic downturn with general loss of confidence in the financial markets the conditional APM with time varying betas and conditioned on the set of instrumental variables used by investors is able to pick up the extreme market volatility in its betas for each factor. As a consequence produces much better estimates. The conditional APM has a weighted average cost of equity capital for all industries of $14.3 \%$ from 2007 to March 2014, while the unconditional APM cost of equity capital for the same period is $10.8 \%$. The average risk premium for the conditional APM varies per month 
and more than doubled from $0.4 \%$ per month before the crisis of 2007 to $1.0 \%$ per month at the beginning of 2009. During periods of uncertainty it is expected that investors would require relatively higher compensation for the higher risks they undertake resulting in higher equity risk premium and hence higher cost of equity capital.

Campbell, Giglio and Polk (2013) state that a wave of research has challenged the traditional paradigm in which the equity premium is constant. Our evidence adds to the literature by showing that assuming a constant equity risk premium over times of uncertainty and extreme volatility will lead to errors in the equity cost of capital.

\section{Conclusion}

In this paper we estimate the cost of equity capital for 28 UK industries consisting of 522 companies with a market value of $£ 1,612.907$ billion under alternative asset pricing models. We employ an unconditional-constant APM, conditional-time varying APM and the CAPM in order to compare their relative performance in estimating the UK industry cost of equity capital during our full sample time period and post the 2007 crisis.

We add to the existing literature by showing that during our full time period, the difference in the errors between the unconditional-constant APM and the conditional-time varying APM are extremely small and statistically insignificant. However again during our full time period when we compare the APMs with the CAPM, the CAPM errors are higher; and the difference in the errors between the CAPM with any of the APMs (unconditional APM and conditional APM) is statistically significant.

There has been considerable debate about the relative accuracy of unconditional and conditional models. Our evidence sheds more light on this issue by showing that during our full time period, the conditional or unconditional properties of a model are not so important as it is to identify a model that includes as much as possible the priced factors in the market; During our full sample time period any of the APMs, unconditional APM or conditional APM, do a much better job than the CAPM.

However during times of extreme market volatility, since the beginning of the 2007 financial crisis the conditional time varying APM is the best model with the least errors. During a financial crisis investors and market participants' expectations are revised, uncertainty increases and capital becomes scarce. During this period investors seek to transfer their wealth to less risky assets, such as sovereign bonds. However what we have experienced during the recent financial crisis, is that there has been a subsequent deterioration of sovereign credits, which has exacerbated the uncertainty of returns over the medium to long term investment horizon. The conditional APM incorporates not only the macroeconomic factors at play but also the extreme market volatility. The conditional APM picks up the extreme volatility experienced in the market; since its time varying betas conditioned on a set of instrumental variables manage to capture the extreme uncertainty in the financial markets. Our empirical findings suggest that the question practitioners should ask is not only which model to use? But which model to use depending on current market conditions?

We also contribute to the literature by identifying new statistically significant factors in UK; the S\&P 500 share price index and the UK stock exchange turnover; Furthermore by employing the NLSUR technique to estimate the industry cost of equity capital using macroeconomic factors. This allows us to impose the constraint that the price of risk for each factor is the same for all industries, a basic principle of the arbitrage pricing theory. The factors that we find statistically significant are not specific to any company or industry but have pervasive nature and represent statistically significant factors that affect the entire UK economy.

Our findings have practical implications, practitioners setting the cost of equity capital should be asking: Are we in a new risk premium environment and thus new cost of capital environment? The equity/industry risk premium reflects economic fundamentals and investor risk aversion and can change over time, sometimes very quickly caused by financial shocks to the system (i.e., collapse of large investment firms, sovereign, etc.). Failure to recognise the new equity risk premium and thus cost of equity capital reality will lead to major mistakes. If companies use a fixed cost of equity capital rate as their financial benchmark for long periods of time, regardless of changes that take place in the company or the financial markets, this only increases the possibility of error. In other words If a company frequently applies a very high cost of capital in its project valuations than its true rate, then it will reject valuable opportunities. Whereas using a very low rate will commit resources to unprofitable and economically questionable projects and reduce shareholder value.

\section{References}

Al-Horani, A., Pope, P. F., \& Stark, A. W. (2003). Research and Development Activity and Expected Returns in the United Kingdom. European Finance Review, 7, 27-46.

Antoniou, A., Garrett, I., \& Priestley, R. (1998). Calculating the equity cost of capital using the APT: The impact 
of the ERM. Journal of International Money and Finance, 17, 949-965. http://dx.doi.org/10.1016/S0261-5606(98)00036-9

Antoniou, A., Garrett, I., \& Priestley, R. (1998). Macroeconomic variables as common pervasive risk factors and the empirical content of the arbitrage pricing theory. Journal of Empirical Finance, 5, 221-240. http://dx.doi.org/10.1016/S0927-5398(97)00019-4

Bansal, R., \& Yaron, A. (2004). Risks for the long run: A potential resolution of asset pricing puzzles. Journal of Finance, 59, 1481-1509. http://dx.doi.org/10.1111/j.1540-6261.2004.00670.x

Bower, D. H., Bower, R. S., \& Logue, D. E. (1984). Arbitrage pricing theory and utility stock returns. Journal of Finance, 39, 1041-1054. http://dx.doi.org/10.1111/j.1540-6261.1984.tb03891.x

Cahart, M. (1997). On Persistence in Mutual Fund Performance. Journal of Finance, 52, 57-82.

Campbell, J. Y., Giglio, S., \& Polk, C. (2013). Hard Times. Review of Asset Pricing Studies, 3, 95-132. http://dx.doi.org/10.1093/rapstu/ras026

Campbell, J. Y. (1986). Stock returns and the term structure. Journal of Financial Economics, 18, 374-400. http://dx.doi.org/10.1016/0304-405X(87)90045-6

Campbell, J. Y., \& Hamao, Y. (1992). Predictable stock returns in the U.S. and Japan: A study of long-term integration. Journal of Finance, 47, 43-72.

Campbell, J. Y., \& Shiller, R. (1988). Stock prices, earnings and expected dividends. Journal of Finance, 43, 661-676. http://dx.doi.org/10.1111/j.1540-6261.1988.tb04598.x

Chen, N. F., Roll, R., \& Ross, S. A. (1986). Economic forces and the stock market. Journal of Business, 59, 383-403. http://dx.doi.org/10.1086/296344

Claire, A. D., Priestley, R., \& Thomas, S. H. (1998). Reports of beta's death are premature: Evidence from the UK. Journal of Banking and Finance, 22, 1207-1229. http://dx.doi.org/10.1016/S0378-4266(98)00050-8

Claire, A. D., Priestley, R., \& Thomas, S. H. (1997). The robustness of the APT to alternative estimators. Journal of Business Finance \& Accounting, 24, 645-654. http://dx.doi.org/10.1111/1468-5957.00126

Cooper, I., \& Priestley, R. (2013). The World Business Cycle and Expected Returns. Review of Finance, 17, 1029-1064. http://dx.doi.org/10.1093/rof/rfs014

Elton, E. J., Gruber, M. J., \& Blake, C. R. (2012). An Examination of Mutual Fund Timing Ability Using Monthly Holdings Data. Review of Finance, 16, 619-645. http://dx.doi.org/10.1093/rof/rfr007

Elton, E. J., Gruber, M. J., \& Mei, J. (1994). Cost of equity using arbitrage pricing theory: A case study of nine New York utilities. Financial Markets, Institutions \& Instruments, 3, 45-64.

Fama E. F., \& Schwert. (1977). Asset returns and inflation. Journal of Financial Economics, 5, 115-146. http://dx.doi.org/10.1016/0304-405X(77)90014-9

Fama, E. F., \& French, K. R. (1988). Dividend yields and expected stock returns. Journal of Financial Economics, 22, 3-25. http://dx.doi.org/10.1016/0304-405X(88)90020-7

Fama, E. F., \& French, K. R. (1992a). Common risk factors in the returns on stocks and bonds. Journal of Financial Economics, 36, 1-55. http://dx.doi.org/10.1016/0304-405X(93)90023-5

Fama, E. F., \& French, K. R. (1992b). The cross-section of expected stock returns. Journal of Finance, 47, 427-465. http://dx.doi.org/10.1111/j.1540-6261.1992.tb04398.x

Fama, E. F., \& French, K. R. (1995). Size and Book-to-Market Factors in Earnings and Returns. Journal of Finance, 50, 131-156. http://dx.doi.org/10.1111/j.1540-6261.1995.tb05169.x

Fama, E. F., \& French, K. R. (1996). Multifactor Explanations of Asset Pricing Anomalies. Journal of Finance, 50, 131-155. http://dx.doi.org/10.1111/j.1540-6261.1996.tb05202.x

Fama, E. F., \& French, K. R. (1997). Industry costs of equity. Journal of Financial Economics, 43, 153-193. http://dx.doi.org/10.1016/S0304-405X(96)00896-3

Fama, E. F., \& French, K. R. (2006). Profitability, investment, and average returns. Journal of Financial Economics, 82, 491-518. http://dx.doi.org/10.1016/j.jfineco.2005.09.009

Fama, E. F., \& French, K. R. (2008). Dissecting anomalies. Journal of Finance, 63, 1653-1678.

Fama, E. F., \& French, K. R. (2012). Size, value, and momentum in international stock returns. Journal of 
Financial Economics, 105, 457-472.

Fama, E. F., \& MacBeth, J. D. (1971). Risk, return and equilibrium: Empirical tests. Journal of Political Economy, 71, 607-635. http://dx.doi.org/10.1086/260061

Ferson, W. E. (1989). Changes in expected security returns, risk and the level of interest rates. Journal of Finance, 44, 1191-1217. http://dx.doi.org/10.1111/j.1540-6261.1989.tb02650.x

Ferson, W. E., \& Harvey, C. R. (1991). The variation of economic risk premiums. Journal of Political Economy, 99, 385-415. http://dx.doi.org/10.1086/261755

Ferson, W. E., \& Harvey, C. (1999). Conditioning variables and the cross-section of stock returns. Journal of Finance, 53, 407-432. http://dx.doi.org/10.1111/0022-1082.00148

Ferson, W. E., \& Harvey, C. R. (1993). The risk and predictability of international equity markets. Review of Financial Studies, 6, 527-566.

Ghysels, E. (1998). On stable factor structures in the pricing of risk: Do time varying betas help or hurt? Journal of Finance, 53, 549-574. http://dx.doi.org/10.1111/0022-1082.224803

Goldenberg, D. H., \& Robin, A. (1991). The arbitrage pricing theory and cost of capital estimation: The case of electric utilities. The Journal of Financial Research, 45, 181-196.

Gregory, A., \& Michou, M. (2009). Industry Cost of Equity Capital: UK Evidence. Journal of Business Finance and Accounting, 36, 679-704. http://dx.doi.org/10.1111/j.1468-5957.2009.02135.x

Harvey, C. (1991). The world price of covariance risk. Journal of Finance, 46, 111-158. http://dx.doi.org/10.1111/j.1540-6261.1991.tb03747.x

Lewellen, J., \& Nagel, S. (2006). The conditional CAPM does not explain asset-pricing anomalies. Journal of Financial Economics, 82, 289-314. http://dx.doi.org/10.1016/j.jfineco.2005.05.012

Lintner, J. (1965). The valuation of risk assets and the selection of risky investments in stock portfolios and capital budgets. Review of Economic Statistics, 47, 13-37. http://dx.doi.org/10.2307/1924119

McElroy, M. B., \& Burmeister, E. (1988). Arbitrage pricing theory as a restricted non-linear multivariate regression model. Journal of Business \& Economic Statistics, 6, 29-42.

Pettway, R. H., \& Jordan, B. D. (1987). APT vs. CAPM estimates of the return generating function parameters for regulated public utilities. Journal of Financial Research, 10, 227-238. http://dx.doi.org/10.1111/j.1475-6803.1987.tb00493.x

Poon, S., \& Taylor, S. J. (1991). Macroeconomic factors and the UK stock market. Journal of Business Finance and Accounting, 18, 619-636. http://dx.doi.org/10.1111/j.1468-5957.1991.tb00229.x

Roll, R., \& Ross, S. (1980). An empirical examination of the arbitrage pricing theory. Journal of Finance, 35, 1073-1103.

Roll, R., \& Ross, S. (1983). Regulation, the capital asset pricing model and the arbitrage pricing theory. Public Utilities Forum, 111, 22-28.

Roll, R., \& Ross, S. (1984). A critical re-examination of the empirical evidence on the arbitrage pricing theory: A reply. Journal of Finance, 39, 347-350.

Ross, S. (1976). The arbitrage pricing theory of capital asset pricing. Journal of Economic Theory, 13, $341-360$. http://dx.doi.org/10.1016/0022-0531(76)90046-6

Rozeff, M. (1984). Dividend yields are equity risk premiums. Journal of Portfolio Management, 11, 68-75.

Schink, G. R., \& Bower, R. S. (1994). Application of the Fama-French model to utility stocks. Financial Markets, Institutions \& Instruments, 3, 56-78. http://dx.doi.org/10.3905/jpm.1984.408980

Sharpe, W. F. (1964). Capital asset prices: A theory of market equilibrium under conditions of risk. Journal of Finance, 19, 425-442. http://dx.doi.org/10.2307/2977928

Shiller, R. J. (1984). Stock prices and social dynamics, Brooking Papers Economic Activity, 2, $457-510$. http://dx.doi.org/10.2307/2534436

\section{Notes}

Note 1. Where log return is: $\log$ Variable $_{t}-\log _{\text {Variable }}$ ar-1 $_{1}$ 
Note 2. Due to the large output of results, for space considerations the regressions of the individual industry return on the factors are not included in this paper. However they are available upon request.

Note 3. See for example, Ferson and Harvey (1991, 1993, 1999), Ferson and Korajczyk (1995), Ferson and Schadt (1996), Ghysels (1998).

Note 4. Harvey (1991), Campbell and Hamao (1992), Rozeff (1984), Shiller (1984), Campbell and Shiller (1988), Fama and French (1988), Bansal and Yaron (2004).

Note 5. Carrying out this exercise generates significant amount of output. For space considerations these regressions are not included in this paper. However all results can be provided upon request.

Note 6. Please see section 5.2 Conditional Betas Estimation for more information.

\section{Copyrights}

Copyright for this article is retained by the author(s), with first publication rights granted to the journal.

This is an open-access article distributed under the terms and conditions of the Creative Commons Attribution license (http://creativecommons.org/licenses/by/3.0/). 